\title{
COVID19 and Human Right To Food: Lived Experiences of the Urban Poor in Kenya with the Impacts of Government's Response Measures, A Participatory Qualitative Study
}

Elizabeth Wambui Kimani-Murage ( $\square$ ekimani@aphrc.org )

African Population and Health Research Center

David Osogo

African Population and Health Research Center

Carolyn Kemunto Nyamasege

University of Tsukuba

Emmy Kageha Igonya

African Population and Health Research Center

David Otieno Ngira

African Population and Health Research Center

John Harrington

Cardiff University

\section{Research Article}

Keywords: COVID-19, response measures, right to food, vulnerable populations, Kenya

Posted Date: November 17th, 2021

DOI: https://doi.org/10.21203/rs.3.rs-1067664/v1

License: () (1) This work is licensed under a Creative Commons Attribution 4.0 International License. Read Full License 


\section{Abstract \\ Background}

Globally, governments put in place measures to curb the spread of COVID-19. Information on the effects of these measures on the urban poor is limited. This study aimed to explore the lived experiences of the urban poor in Kenya in the context of government's COVID-19 response measures and its effects on the human right to food.

\section{Methods}

A participatory qualitative study was conducted in two informal settlements in Nairobi between January and March 2021. Analysis draws on eight focus group discussions, eight in-depth interviews, twelve key informant interviews, two photovoice sessions and three digital storytelling sessions. Phenomenology was applied to understand an individual's lived experiences with the human right to food during COVID -19. Thematic analysis was performed using NVIVO software.

\section{Results}

The human right to food was affected in various ways. Many people lost their livelihoods affecting affordability of food due to response measures such as social distancing, curfew, and lockdown. The food supply chain was disrupted causing limited availability and access to affordable, safe, adequate, and nutritious food. Consequently, hunger and an increased consumption of low-quality food was reported. The government and other stakeholders instituted social protection measures. However, these were inadequate and marred with irregularities. Some households resorted to scavenging food from dumpsites, skipping meals, sex-work, urbanrural migration and depending on food donations to survive. On the positive side, some households resorted to progressive measures such as urban farming and food sharing in the community. Generally, there was a view that the response measures could have been more sensitive to the human rights of the urban poor.

\section{Conclusions}

The government's COVID-19 restrictive measures exacerbated the already existing vulnerability of the urban poor to food insecurity and violated their human right to food. Future response measures should be executed in ways that respect the human right to food and protect marginalized people from resultant vulnerabilities.

\section{Introduction}

Coronavirus disease 2019 (COVID-19) was declared a pandemic by the World Health Organization (WHO) on March, 112020 [1]. Governments enforced control strategies to "flatten the infection curve"[2], in response to measures suggested by the WHO and Center of Disease Control (CDC) [3]. For instance, governments restricted international travel through border shutdowns, strict quarantine measures, curfews, closures of businesses, restricting social and sporting activities likely to generate crowds among many others [4]. 
Majority of low- and middle-income countries (LMICs), which have adverse social determinants of health and system challenges, quickly responded to the pandemic by employing their resources to implement the COVID-19 control measures. For instance, India was praised by the WHO for being 'tough and timely' in declaring a nationwide lockdown that affected 1.3 billion persons [5]. Sub-Saharan African countries such as Ghana, Sudan and South Africa responded quickly to contain the spread of COVID-19 by implementing lockdown measures [6]. Equally, the government of Kenya promptly implemented measures such as suspension of international flights, partial lockdown, school closure, curfew, compulsory wearing of masks, a ban on social gatherings, restriction of business operating hours, social distancing and cessation of movement across cities following a marked rise in the COVID-19 cases [7, 8]. Incidentally, these restrictions to mitigate the pandemic have contributed to vulnerabilities such as strained socioeconomic activities, uncertainty, anxiety, mental distress, loss of livelihoods and violation of human rights as reported in previous studies [9, 10]. Moreover, disruption of food systems has heightened food insecurity while the financial power to access food has been affected as reported in a study conducted in Uganda and Kenya [11].

A report by the United Nations (UN) on Covid-19 and human rights states that governments may exercise limits on certain human rights to contain national emergencies, as this is recognized by the human rights law [12]. Response measures shaped by respect for human rights lead to better outcomes in overcoming pandemics, preserving human dignity and ensuring healthcare for all [13].

Food is a human right, recognized under Article 25 of the Universal Declaration of Human Rights (UDHR) as part of an adequate standard of living [14]. This was expanded upon in Article 11 of the International Covenant on Economic, Social and Cultural Rights (ICESCR), which establishes the inherent human right to adequate food, [15]. Further, the Committee on Economic, Social and Cultural Rights (CESCR) issued a general comment No. 12 (1999) that defines the right to adequate food as "the right to feed oneself and one's family with dignity, through sufficient availability, accessibility, and adequate fulfilment of dietary needs in a sustainable manner". This is realized "when every man, woman and child, alone or in community with others, has physical and economic access at all times to adequate food or means for its procurement" [16].

Kenya has recognized the right to food, and has ratified various human rights instruments including the ICESCR. Article 43 (1c) of the Constitution of Kenya, 2010 (COK, 2010) recognizes the right to food, stipulating that: "every person has the right to be free from hunger and to have adequate food of acceptable quality". Other related articles in the COK supporting right to food include Article 53 (1c). As stipulated under Article 21 of the COK, the State has a duty to observe, respect (not interfere with one's ability to acquire food), protect (ensure others do not interfere with one's ability to acquire food) and fulfil (either provide an enabling environment for food production or procurement or directly provide food to those who are not able to produce or procure food for themselves and their families due to loss of livelihood, conflict, detention, natural disasters or other reasons) $[17,18]$.

Notwithstanding the above, the right to food continues to face normative challenges. For instance, the domestication of article 2 of the ICESCR under article 21 (2) of COK which mandates the state to 'take legislative, policy, and other measures to achieve progressive realization of socio-economic rights' poses a challenge to Kenya's government obligation to right of food to citizens. The doctrine works on the presumption that the state does not have limitless resources and that all that it needs to show, is that it is working towards the full realization of the right in question, [19]. This reality has not only acted as a claw back clause in the 
protection of the right to food but has also made the right less justiciable despite the existence of constitutional protections under article 43 (1) (c). The principle of progressive realization also presumes that countries with greater resources have a higher obligation to realize socio-economic rights than poor ones, and that a country's obligation as a duty bearer increases with its increase in economic development (Ibid: 6) [19]. However, Kenya has not complied with this conception because the increase in its economic development over the last 20 years has not resulted into any corresponding increase in the protection of the right to food.

Despite the right to food being recognized as a basic human right by all countries except Australia and the United States of America, during the Rome Declaration on World Food Security in 1996 [20], many people globally are food insecure. About 720-811 million people worldwide, mostly women and children, are foodinsecure (a lack of consistent access to enough food for every person in a household to live an active, healthy life) [21]. This problem is also evident in Kenya. Previous research indicated that majority (over $80 \%$ ) of the households in the urban informal settlements of Nairobi were food insecure [22]. A report on the threat posed by the pandemic to food security states that the four pillars of the rights to food and food security, recognized by the UN Committee on Economic, Social and Cultural Rights, namely availability, accessibility, utilization and stability have been affected by measures taken to stop the spread of COVID-19 [23]. Consequently, this threatens the achievement of the Sustainable Development Goals (SDGs) such as ending poverty, achieving zero hunger, good health and wellbeing, among others [24]. Moreover, as the UN Committee has indicated, ensuring freedom from hunger is a core obligation on states, which it must to discharge as a matter of priority making every effort possible [16].

As with all crises, the consequences of the COVID-19 outbreak are felt most acutely by those already marginalized in society. Information on their experiences is essential to understanding the extent to which basic human rights, guaranteed nationally and internationally, have been secured. Moreover, the value of participation is a cornerstone of Kenya's constitutional system, and recognized as an essential element of international human rights $[25,26]$. Yet studies reporting on the vulnerability of the urban poor and their lived experienced regarding their right to food in the context of COVID-19 restrictive measures are limited. In filling this gap, the present study was conducted in urban poor settings in Kenya during COVID-19. Our research was guided by the human rights framework and specifically the framework of the right to food namely availability: whereby food should be available from production by cultivating land or animal husbandry, from natural resources, fishing, hunting and gathering; accessibility by ensuring economic accessibility in terms of affordability without compromising other basic needs and physically accessible to all including the vulnerable in the society; adequacy to meet an individual's dietary needs while considering a person's age, sex, living conditions, occupation, health, etc. The study aims to explore the experiences, perceptions, and attitudes of vulnerable citizens in the informal settlements of Nairobi with regards to the impact of the government's COVID-19 response measures on the human right to food.

\section{Methodology}

\section{Study design and approach}

This was a qualitative participatory study aimed to document the lived experiences of the community members. Phenomenology was applied to understand an individual's lived experiences concerning the human right to food during COVID -19. Through the phenomenology approach, authors seek to describe the essence of a 
phenomenon from the perspective of those who have experienced it, with a goal of describing the meaning of their experience in terms of what and how it was experienced [27]. Specifically, Dahlberg's reflective life world approach was applied [28]. Both hermeneutic (interpretive) and transcendental (descriptive) phenomenology were applied during data collection, analysis, and presentation of the results.

\section{Study settings}

This study was carried out in Korogocho and Viwandani, low-resource informal settlements, in Nairobi, Kenya [29] from January -March 2021. The two urban informal settlements are about seven kilometers apart covering a total area of approximately one $\mathrm{km}^{2}$ with about 89,000 individuals from 33,500 households [30]. The informal settlements are densely populated with more than 60,000 inhabitants per square $\mathrm{km}$ and are characterized by poor housing, lack of basic infrastructure, violence, insecurity, high unemployment and poverty rates, food insecurity, and poor health and nutrition indicators [29].

\section{Study population and sampling}

The study participants were residents of Korogocho and Viwandani and selected community leaders including area chiefs, village elders, ward representatives, and senior health officials. These participants were conveniently selected to get a fair representation from the communities. Selection of participants for Focus Group Discussions (FGD), photovoice and digital stories was based on their knowledge and experience in the government's response measures to COVID-19 in urban informal settlements. Besides selection for participants of In-depth Interviews (IDI) and Key Informant Interviews (KII) was based on the perceived critical role they play in these areas. Convenience and purposive sampling technique was used in identifying eligible participants. They selected a consecutive sample of older and younger male and female community members to ensure a representative age and gender.

\section{Data collection methods and sample size}

Qualitative data collection techniques; FGD, IDI, KII, and participatory research methods, mainly photovoice and digital storytelling were employed in data collection to understand, and document lived experiences of the participants. A total of eight FGDs, each involving a total of six homogeneous participants were conducted: four in each site (Korogocho and Viwandani). The participants included separate groups of women, men, youth, and traders in each study site. Besides, a total of eight IDIs were conducted, four in each site. The IDI participants were adult men and women. In addition, twelve Klls were conducted with community leaders (chiefs, village heads, ward administrators, religious leaders, Community Health Volunteers (CHVs, and public health nurses $(\mathrm{PHN})$, six in each site.

Participatory methods such as photovoice and digital stories were also used to document lived experiences of the community members with government's COVID-19 response measures. Through photovoice, a participatory and visual research methodology, participants used photography to identify, capture, and express issues with respect to certain aspects of their lives [31]. Participants produced a short video clips through digital storytelling, also a participatory method, of telling their story in a compelling and emotionally engaging and interactive format [32]. A mixed group of both youth and adults was engaged in each site for the photovoice activity, with each session having six participants. A similar group was engaged in each site for digital storytelling activity. 
Photovoice participants received cameras and were trained on basic photography skills by the research team. They were asked to take photographs that depict their perspectives and lived experiences with government COVID-19 measures and the impact on their lives. Thereafter, they developed captions for their photos and held discussions to tell the stories depicted in their photos. In digital storytelling, participants were guided through scripting and development of their stories, narration, and shooting (recording), and editing to produce a good story. The stories were then screened in a session for the participants themselves to critique and help improve them to the best quality and final versions.

\section{Data analysis}

Data was analyzed thematically based on the right to food framework [26]. Familiarization of the data began in the field, evolving together with data collection, and it involved various steps based on thematic analysis of qualitative data [33]. Firstly, a review of the collected data was done (transcripts and audio) by the qualitative field interviewers through field debrief sessions, at the close of each interview day. Through these sessions, the team jointly identified and documented emerging salient topics and themes in relation to the research objective. A debrief form reflecting the research question was developed for reference. Secondly, was the verbatim transcription of all interviews and photovoice discussions in word format.

Individual transcripts were thoroughly read and scrutinized by the data analysis team while identifying and creating codes based on relevant meaningful patterns across respondent groups. The identified responses relevant to the research question were clustered according to similarities while categorizing subthemes inductively. Three themes were identified namely: lived experiences with the impact of government's COVID-19 response measures on livelihoods and food security; human right to food in regard to food availability, accessibility and adequacy; social protection and coping strategies in regard to food acquisition. Further, an exhaustive, condensed description of the responses was generated. Coding was conducted by two researchers and a code book was generated and shared with all the research team for reference and agreement with the coding. Data organization and coding was performed using NVIVO, a Qualitative Data Analysis (QDA), software [QSR International Pty. Ltd., Melbourne, VIC, Australia] (release 1.5 for Windows).

Adherence to government protocols and the research institution's data collection guidelines in the context of COVID-19 pandemic were observed during data collection. Further, face-to-face engagements were conducted in open spaces and in spacious and well-ventilated rented rooms, to adhere to social distancing guidelines (at least $1.5 \mathrm{~m}$ between the respondent and the interviewer). Researchers provided hand sanitizers and face masks to all participants and data collectors during face-to-face interviews.

\section{Results}

\section{Characteristics of the study participants}

A total of 80 adults participated in this qualitative study. Forty-eight people participated in the FGDs, eight in the IDIs, 12 in the KIls and 12 in the photovoice. However, personal characteristics of 17 participants' (12 KIIs and 5 IDIs) were not collected. Out of the 63 participants, their age ranged from 18-58years with a mean (SD) age of 37.1 (12.7). Most of the respondents were either married (50.8\%) or single (38.1\%), had primary (46.0\%) or secondary school (42.9\%) level of education and were either doing business (47.6\%) or casual labor (27.0\%) 
while most of the youth (<24years old) were either casual labors (29.4\%) or unemployed (38.5\%). The proportion of male (49.2\%) and female (50.8\%) participants was almost the same, Table 1.

\section{Government's COVID-19 response measures and their effects}

The main COVID 19 response measures included measures that were seen in a positive light including: provision of water tanks, taps and soap for hand washing and hand sanitizers in the community particularly outside business premises, and strict observance of proper sanitation and hygienic practices. Other measures, generally seen in a negative light from a socio-economic perspective included dusk to dawn curfew; partial lockdown where schools, places of worship, bars and restaurants were closed; restricted movement from and to Nairobi County; quarantine measures; compulsory use of face masks; social distancing, where people were encouraged to stay at home, not to shake hands or hug or not to meet in big numbers for example in social gatherings such as weddings and burials.

Alongside the primary COVID-19 response measures, participants reported other measures put in place by the government in partnership with Non-Governmental Organizations (NGOs), faith-based organizations, private stakeholders, and well-wishers to promote compliance with the preventive measures and to cushion the effects of the restrictive measures. To ensure compliance, strict enforcement measures using police, village elders, chiefs, and heads of "Nyumba Kumi Initiative" (a government strategy to complement community policing at household level) were used.

In enforcing the response measures such as dusk to dawn curfew, the police in some instances were reported to use excessive force contributing to increased police brutality in the informal settlements. Other forms of police harassment including intimidation and bribes also characterized this period. The abuse of human rights was therefore reportedly a common effect of the response measures.

Generally, the community believed that certain measures were inappropriate for the slum settings and were insensitive to their social economic context. Social distancing for example, was mentioned as non-social and non-economic-friendly in the context of the slum setting. Economically, it had a negative impact on jobs. Socially, according to the local administration participants, it would be impractical to implement where people share amenities such as toilets and shower rooms. Masks were reported to be unaffordable in these communities.

Below is a focus on the lived experiences with the COVID 19 measures, specifically on the lived experiences with food security and the human right to food.

\section{Lived experiences with regards to food security and the human right to food}

The government's COVID19 response measures were reported to have serious impacts on the livelihoods of the urban poor residents due to loss of jobs, and disruption on business. The impact of the measures on livelihoods consequently had dire impact on food security and the right to food. Additionally, food security and the right to food was affected directly by the government response measures. Firstly, authors describe the impact of response measures on socioeconomic status, and a spillover effect on food security, focusing on food availability, food accessibility and food adequacy, highlighting how the right to food was violated. Lastly, results are presented on mitigation measures put in place by the government and partners to alleviate the 
impacts on food security and the right to food and the copying strategies employed by the community regarding food acquisition.

\section{Livelihoods}

Participants suggested jobs/employment (including causal labor/wages in local factories), businesses (petty or small business) and scavenging food from the dumpsite were the main facilitators of food acquisition in the two study sites. A lot of people living in the informal settlements work in the industries in these settings. The study suggests these industries were forced to reduce staff to comply with social distancing and curfew measures and to cope up with reduced production due to interruption to the market and supply chain. Many other employers also sent their employees home due to the measures and related disruptions. Besides, lockdown and social distancing limited casual laborers from accessing their area of work and employer's fear of getting infected in the case of dayshift house servants. Consequently, many people lost their livelihood sources because of loss of jobs and disruptions caused by these measures.

"... This is the effect of COVID-19 and as you can see in the picture people are idle. So, people have lost their jobs so the picture represents how people are idle in the community." (Photovoice, mixed participants, Korogocho).

Thirty-two-year-old Purity K (pseudonym), a mother of four children and a primary school dropout explains her experience with loss of job when COVID-19 struck as she explains in her digital storytelling [34]:

"My parents were not able to pay my school fees, so I dropped out of school in class seven. When I was 23 years, I was lucky to get a job at a factory. Before the corona pandemic was in the country, life was not so hard. We had enough food to eat, clothes to wear, there was happiness in my family. After the pandemic [struck], life became harder. The factory laid me off due to COVID 19 measures like social distancing. Life became hard because of the responsibilities, and I did not have money to care for my children. I did not have money to pay rent. Eventually, my neighbors took my children to feed them because I was not in a position to do so. Now that life is a little bit back to normal, I tried going back to my old job however due to lack of education; I did not manage to get my old job back. People who have higher education than me and had previously lost their jobs are the ones who are doing my job right now". (Purity, digital storytelling speaker 1).

Purity's experience resonates with experiences of other research participants suggesting the impact of COVID 19 on loss of jobs affecting access to food. In her digital storytelling, Mama Wangechi (pseudonym), married with four children living in Korogocho tells her predicament with coronavirus [35]:

"Before corona, my husband used to work at an industry in Baba Dogo. Life was good before corona. Ever since the pandemic, life changed. My husband lost his job at the industry because the company reduced its production and the government put in measures for example social distancing [...] Food became hard to find due to change in income [...] The situation at home worsened and [...] the arguments at home every day led to my husband leaving and I was left alone with the children" (Mama Wangechi, digital storytelling speaker 2).

Moreover, many businesses were also shut down in compliance with the regulations while some had to close due to persistent losses. Curfew hours affected businesses most as many thrive well in the evening and at night, when customers come from work to buy stuffs, while cessation of movement and border restrictions 
disrupted the supply chain which affected businesses. The resultant reduced purchasing power of the customers, also negatively affected businesses.

"...Businesses were affected because there were shops that were closing at eleven or ten but when the curfew was imposed, they couldn't close late and that affected their business which has reduced their incomes..." (Photovoice, mixed participants, Viwandani).

"...Personally COVID-19 has really affected us because my husband lost his job, the business I had was also affected because the customers also lost their jobs, so they didn't have money - the few that are there all ask for debts and they don't even repay it sooner. You need food but don't have money to buy the food so it really affected us." (FGD, adult females, Viwandani).

\section{Food security and violation of the right to food}

Participants narrated how the government response measures impacted on their food security and violated their human right to food. Loss of livelihoods and movement measures compromised access and food supply respectively, and resulted in limited access to safe, adequate, nutritious food, and therefore violated the right to food.

"...A child has the right to food and humans have right to food, but you don't have the means to look for the food so that right is already violated. So, unless they would get these organizations to support, and they wouldn't support the whole community so some people would still miss out. That was discrimination on the right to food" (FGD adults female Korogocho).

In her digital storytelling, Mama Wangechi', noted how they family moved from three meals a day to water only [35].

"Earlier [before COVID 19] we used to have meals thrice a day, but things changed since Corona came. We used to drink tea with milk but nowadays we drink hot water .... or borrow from the shops and from the vendors in the neighborhood but not every day because they would not accept" (Mama Wangechi, digital storytelling speaker 2).

Participants in the FGD consisting of traders reported that food vendors had their small businesses closed by the local authorities for not complying with hygienic measures such as provision of water and soap for customers to wash hands before being served. Moreover, police prevented people from accessing food within the curfew times or those not observing the restrictive measures. Besides, with loss of livelihoods, food prices were unaffordable to community members. The FGD participants intimated that the government, in not intervening to reduce food prices, failed to respect and protect the vulnerable on their right to food.

While the perspective of community members, the measures interfered with human rights, by contrast, the local leaders had a different view. For them existence above all is at the core of human rights. Thus, they considered that the government upheld human rights by virtue of the fact that it moved quickly and irresolutely to put in measures against the very real threat posed by COVID-19: loss of human lives.

The rest of this study further suggests how the different aspects of the right to food: food availability, food access and food adequacy were affected by the government COVID19 response measures. 


\section{Food availability}

Curfew and lockdown particularly movement restriction were government measures voiced out by many participants as negatively affecting food availability. The quantity and variety of food sold by community vendors in the market were affected. For instance, curfew limited traders from accessing the wholesale markets early enough, normally at dawn, to obtain the best of the produce in terms of quality, variety, and lower prices. The food supply chain was also disrupted by the national lockdown, border shutdown, cross-border restrictions such as requirement of COVID 19 tests and certificates, long queues, high cost of transportation, and the cumbersome requisition of expensive permits to transport food from rural to urban settings due to the movement restrictions. As a result, FGDs, KII and photovoice participants suggested supply of food mostly vegetables, fruits and cereals including those imported from neighboring countries was limited, considering their perishable nature.

You know there were people who transported the foods from upcountry to sell here and when the curfew was imposed it was expensive to apply for travelling letters and the cost of food had to increase. So only a little food was available, and it was also expensive" (FGD, traders, Viwandani)

Moreover, some vendors reduced the quantity of food because of lowered purchase power of the community members to avoid making losses, while others closed their businesses owing to fear of contracting the virus, COVID-19. Furthermore, many people left Nairobi for rural area, which contributed to low purchase power.

"...Businesses reduced because people were few in the community and those who were working also reduced so business was really affected. If you look at the photo you will see the market is almost empty.

So, businesses went very low..." (Photovoice, mixed group, Viwandani).

Likewise, suspension of international flights and closing of hotels disrupted availability of free and cheap food from the dumpsite as some residents and traders scavenge leftover food such as yoghurt, fish, milk, bread, sugar, burgers, disposed by airlines in Dandora dumpsite, one of the largest dumpsites in Nairobi.

"Sometimes we do get fish or yoghurt that is dumped when the planes fly in, and they are left in the planes." (FGD, adult males, Korogocho).

In addition, some food commodities were out of stock, mostly those sold in supermarkets, because some people who could afford were said to buy large quantities of foodstuffs such as flour and stock them for future use due to fear of uncertainty given the COVID19 crisis. However, some participants had divergent views as they acknowledged that most of the food commodities were generally available though expensive.

\section{Food accessibility}

Participants narrated that majority of the of urban informal residents' access food through purchase. They also live hand to mouth with minimal or no savings at all and mostly depend on small businesses and casual labor as a source of livelihood. Closure of industries, restaurants, limited the sources of individual and household income while curfew affected petty traders who depended on evening customers, hence, constrained food accessibility due to limited purchasing power. 
Besides, the cumbersome process of getting food into the market affected by measures such as curfew, lockdown and social distancing in passenger vehicles increased food transportation costs resulting in increased cost of acquiring food by the traders. Subsequently the traders hiked the prices of food to recover their expenditure hindering affordability of the basic food commodities.

"... The prices of things that people use daily such as food, water and soap were hiked due to the curfew and change in business hours due to COVID-19. So, you find that if you were buying a sack of maize at two thousand shillings, now it costs two thousand five hundred because they (vendors) have risked to bring it from the farms and the measures also make it such that if they were to bring five sacks of maize in a day, they end up bringing two or three because of cessation of movement during curfew time. So, the products found in the shops also had their prices hiked because the transportation time has been reduced...." (Photovoice, mixed group, Viwandani).

During normal times, some community members normally buy their food at distant wholesale markets where the prices are lower, some of which require the use of public transport (Matatus) to get to the markets. The Matatus increased their fares to take care of the reduced capacity as they were restricted to carrying passengers only up to $60 \%$. The cost of accessing the preferred markets therefore went up, sometimes not making economic sense to the people who would have liked to go for food there, and many resorted to walking or opted out of this traditionally popular option. As such, the accessibility of food through this channel was also disrupted.

"...It was a challenge because you would find that kales were cheaper in Muthurwa (wholesale market) but transport cost was double so you would have to walk to buy the cheaper kales. So, the high transport cost also made it a challenge...." (FGD, adult males, Korogocho).

The curfew restricted business hours, which meant that people would not access food during the curfew hours because the food kiosks and markets would be closed. Some people would get back home late in the evening after a long day of work with the intention of buying food for their families only to realize that the businesses had been closed. People who were working who found businesses closed would still go hungry in this case, not because of lack of money but because food was not there at the time they left work. The curfew times therefore posed a hindrance to food access for some people owing to the nature of their jobs.

"...Also, you would find that for the vegetable sellers, I would (for example) have money after doing my job and earning from it but I cannot buy food because of the curfew, and they (food vendors) have closed. So, I would sleep hungry and yet I have the money..." (FGD, adult males, Korogocho).

Family separation because of domestic violence aggravated by unemployment, inability of the household head to provide for the family and idleness, increased dependency on a single parent who was not able to entirely access enough food for his/her family.

\section{Food adequacy}

Food adequacy was affected in regard to quality, safety, and household food distribution. Inability to access food led to consumption of low-quality food which was inadequate to meet their dietary needs. Their goal was 
to fill the stomach irrespective of food quality and diversity. Reportedly, many households only afforded to eat one meal a day, mostly dinner, because they were unable to afford three meals a day [35].

Moreover, they were uncertain about their next meal due to low purchasing power and unstable supply of food as a result they rationed the foodstuff received from food-aid to save some for subsequent days. School closure also increased household budgeting and affected household food distribution as some parents depended on school feeding programs when schools were in session to cut down their food expenditure. Additionally, others had to compromise on their food choices by eating only available food despite their health conditions such as diabetes, hypertension which require modified dietary habits.

"...We have a food problem in Korogocho; if you have twenty shillings or thirty shillings you would use it to feed your family by buying superdip (powdered juice) and anyona, the bread (made of rejected breadcrumbs) that cost ten shillings ( $\$ 0.1) "$ (FGD, adult females, Korogocho).

Food quality and safety was also a problem as narrated my many of the participants. Low purchasing power reduced consumer's demand for food from the local traders who vend by the roadside or in small kiosks. Moreover, businesses were closed earlier than usual in compliance to curfew measures. Therefore, there was carry-over of left-over cooked food to the next business day to reduce losses, hence reduced freshness of food being sold. Respondents recounted that some restaurants reduced the quality of food e.g., by increasing the amount of water "soup" in the food so as to increase the amount of food to meet customers' demand.

"... The photo shows a challenge as there is food, but they are not eaten. So, it has affected the community because they don't have money and that's why the businesses people will sell their products for two days or a week and that is costly to them. And it is not even safe as we are supposed to eat fresh foods. But since there is no money people will not buy fresh foods and it's not their liking..." (Photovoice, mixed group, Viwandani).

Some participants indicated that they fed directly from the dumpsite by scavenging food or buying cheaper dumpsite food from the roadside vendors, which is mostly leftovers from the restaurants, disposed expired food from supermarkets, or rejects from the industries. This resulted in consumption of low quality, expired, unhygienic and stale food.

"So, what we don't always understand is that why are these foods always dumped here. So, if you eat them and you don't get affected then you will make it a routine. So that's what the people survived on" (KII religious leader Korogocho).

The situation of food insecurity in the community was reported to increase the cases of malnutrition in the community, particularly in young children, as reported by the health care professionals.

"...It did affect their nutritional status. We had increased cases of malnutrition in the community especially amongst the under-fives..." (KII, PHN, Viwandani).

The government through the media and local authorities has made efforts to provide means of promoting proper sanitation and hygienic practices and sensitizing the community on boosting immunity by eating a balanced diet and physical exercise. Likewise, participants recounted improved knowledge and awareness on 
healthy living and practices. However, a balanced diet and physical activity was very unlikely due to food insecurity, lack of money and restrictions of movement, respectively.

"The government also helped us by asking us to do physical practice so that we could boost our immune systems and also to try and balance our diets by eating a lot of fruits and greens" (FGD, adult females, Korogocho).

\section{Social protection measures and coping strategies regarding food}

\section{Social protection measures}

The government and partners including non-governmental organizations (NGOs), the private sector, faith-based organizations and community-based organizations played a role in partially fulfilling the human right to food. This was through provision of food-aid, cash transfers to the most vulnerable households/individuals. Further, the government and partners provided free water supply, soap and sanitizers which helped curb the spread of the pandemic but also promoted food security in terms of promoting food hygiene. Some people also reported that they used the water to establish kitchen gardens.

"The food aid was quality because they would give out even a kilo of rice and a kilo of sugar and that would be good - also they would give out a kilo of beans so you would boil the rice and beans and that would be a good meal so even those who brought food aid really tried to give out balanced diet" (FGD adults male Korogocho).

"... We also had the government together with other partners putting in place hand washing points in various areas. We also had other partners coming in to provide cash transfers to most vulnerable patients like HIV and TB patients and those malnourished ..." (KII, Public Health Nurse, Korogocho)

Similarly, from the digital storytelling, Mama Wangechi tells how she has benefited from social protection from the INGOs [35]:

"After a while, the village elder called me and helped me get funding from OXFAM Red cross. Within a month, I got the money, and I was very happy because I was among the lucky few, as some people did not get the money. I paid my rent and the food I had been taking on credit from the shop and the vendors. [...] I am grateful especially to the Red Cross for giving me the money. Without them, I would not have opened my food vending business" (Mama Wangechi, digital storytelling speaker2)

The government introduced an economic empowerment program called "kazi mtaani" which targeted the jobless youth. They would be enlisted into the program and assigned paid work within the community, mostly on environmental cleaning and sanitation. Community members appreciated this gesture.

“... Kazi mtaani has really assisted youths - not only those youths, but they also have parents, and some have really assisted their parents through the earning though kazi mtaani..." (KII, Senior Chief, Korogocho).

However, the social protection measures were short-lived, lasting only about four months, and their implementation was marred by challenges such as limited coverage against a very large population, irregularities, and discrimination in distribution as it was not universal, yet all the residents of urban informal settlements are considered vulnerable. The use of police force by the government to ensure compliance of the 
measures was met with a lot of criticism. Respondents reported brutal harassment and extortion in form of bribes in case found not to comply with the measures. Besides, some community leaders and chiefs were accused of injustices, corruption by requesting bribes to extend favors, inequality, and unfairness in targeting and recruiting eligible members for food-aid and cash transfers. Consequently, vulnerable community members spent the extra coin they could have saved for food purchase in bribing the police and local authorities.

"There was some cash transfers that was supposed to be sent to the citizens, the truth of the matter is that the officials are the ones getting the cash transfers. When an administrative leader comes, they are bribed - when food is brought for distribution, the administrative leader takes most of it" (FGD youths, mixed group).

\section{Coping strategies}

The disruption of livelihood sources compounded by the pre-existing socio-economic vulnerabilities of the members of informal settlement communities forced them to unpleasant coping strategies. Scavenging food from the dumpsites was one of the popular coping strategies.

"...So, the children are at home, and they scavenge the dumpsite for food and if they find something else that they can sell they also go and sell it and get some money to buy something to eat. So all this is the effect of Corona virus which also caused lack of jobs..." (Photovoice, mixed group, Korogocho).

Skipping meals was also popular among the respondents. This resulted from reduction of the household sources of income as the household head, and one or two members of the household lost their livelihood. Some resorted to having one meal a day, in a bid to reduce consumption and save for the next day. They considered dinner (supper) as their most important meal while others managed to eat two meals a day.

"So, it ended up that either we have breakfast and skip lunch so that we can have supper. So, food was a challenge and even now food is still a challenge in Korogocho" (IDI adult female Korogocho).

Participants suggested that limitations in sources of income resulted in socially undesirable or illegal and alternative coping strategies such as child labor, sex work and theft as means for survival. Food insecurity vulnerabilities caused parents to engage their children in income generating activities such as hawking, bordering on child labor in violation of children rights. Some were engaged in begging and scavenging activities. Young girls and married women were lured into sex work to earn income to purchase food. Some engaged in these activities with the consent from their parents. "So, you find that it's very easy for the mother to give out their first-born daughter in order to feed the other young children". It was reported that young people engaged in sex work for food. This led to teenage pregnancies, increase in sex work, child labor, substance use and school dropouts as narrated in the digital story telling by Mama Awiti (pseudonym), [36].

". Children decide to walk around and if they find an older man who promises them something, they will indulge into sex. So many girls got pregnant while boys started stealing. They started breaking into people's homes and sell whatever they stole to get daily bread" (IDI youth female Korogocho).

Some community members depended on borrowing money from friends and Safaricom, a mobile phone company, which has a platform called "mshwari", a saving and loaning service using the "MPESA" mobile money app, food donations sent by their relatives living in the rural areas whereas, others resorted to migrate 
back to their rural homes or send their children to rural areas due to lack of enough money to sustain everyone. Additionally, some engaged in alternative livelihood sources, including economic activities they previously considered inferior to their level such as doing laundry for others at a fee, hawking facial masks, prostitution, picking plastics and metals from dumpsites for sale and doing construction jobs for a lower pay due to low demand for labor.

Some community members started engaging in progressive coping strategies such as engaging in urban farming during this period to produce food for their consumption. They used varied innovative methodologies that could enable them to engage in farming within their limited spaces. This was also enhanced by the increased availability of water within the informal settlements that was aimed at enhancing hygiene practices such as hand washing within the slum communities.

"... There were people who started thinking about farming... If you walk in Korogocho you will realize that there is somebody with something small like a garden - something small in most of the areas... I remember there was this group... - they even planted mushrooms.... So they decided to plant mushrooms and they were selling to people. There are also people who have kales within their residential places..." -KII, CHV, Korogocho "... On my side, there was a time I was idle, and I didn't have any work so I started doing some farming because we had water the whole time of the pandemic - so I grew some kales and spinach which would always support me. Whenever I had flour, I would just get kales or spinach from the farm and eat them..." (FGD, adult females, Korogocho).

Notably, some people embraced the spirit of 'Ubuntu' - I am because we are - and minded their neighbors through sharing whatever little they had.

"... whoever got food would share with the rest as they waited for the other distribution. So, the food was not distributed throughout... so that's why we made groups in our community, if people from this group received, they would share with the others and when they also received, they would also share" (IDI, adult females, Viwandani).

\section{Discussion}

This study aimed to explore the lived experiences of vulnerable citizens in the informal settlements of Nairobi with regards to the human right to food, as guaranteed in the Kenyan Constitution 2010, following government's COVID-19 response measures. Participants narrated that disruptions of the food supply chain and loss of livelihoods affected food availability, food access and affordability and adequacy. This consequently increased vulnerability to food and nutrition insecurity. The community employed various, sometimes unpleasant coping strategies. Despite the government putting in place some social protection measures, participants expressed their negative perceptions on the government's inability to respect, protect and adequately fulfil their right to food. A report on COVID-19 and food systems from the Indo Pacific region indicated similar findings such as disrupted food supply chain owing to both international and local restrictions on logistics, significant loss of employment and incomes and food insecurity and resultant increases in food prices [37].

Various nations had similar measures to control the spread of COVID-19 [4]. However, many governments did not factor in adequate strategies to alleviate the effects of the restrictive measures particularly to the most 
vulnerable populations $[38,39]$. As a result, similar effects of the measures on food security were experienced across the globe [40]. Additionally, the measures have exacerbated an economic crisis, reduced social interaction, increased discrimination, and social stigma particularly to people returning home and health workers as reported in a similar study conducted in Nepal [41].

Though the response measures were intended to protect the people from the infectious virus, they were executed in ways that heightened vulnerabilities of the urban poor and worsened existing human rights violations such as the inherent human right to adequate food and freedom from hunger [42]. For instance, social distancing was reported in other studies across the globe and the United States of America, to contribute to socioeconomic hardships, loss of employment, psychological effects hence a difficult measure to sustain from an economic and financial perspective $[43,44]$. Additionally, lockdown led to anxiety regarding food security as an economic, health, human wellbeing and human rights concern, as conveyed in a study which used qualitative data polled from 12 countries [40]. Moreover, evidences from sub-Saharan Africa and across the globe show that availability and accessibility of food has been limited by disruptions in food chains resulting from governments' lockdown and curfew measures $[45,46]$.

Previous studies have also reported violation of human right to food before and after the pandemic across the globe, in both low-, middle- and high-income countries [42, 47]. For instance, a study conducted in the United States reported violation of the human rights to food as mostly indigenous communities, people of color and those of lower socioeconomic backgrounds were struggling to put food on the table and were living paycheck to paycheck with limited support from the government [20]. While a study in Uganda indicates that the state did not fulfil its obligation under the ICESCR to ensure children have their right to food and freedom from hunger [48].

Notably, the human right to freedom of movement owing to lockdown and curfew has limited the freedom to enjoy other human rights, particularly the right to food [12]. The right to food as stated in Article (Art) 43 [25] of the Kenyan constitution has reportedly not been secured and enjoyed by many people during this pandemic [49]. Moreover, reports show that those charged with enforcing COVID-19 measures such as national and county governments as well as other agencies have violated human rights (e.g. liberty, access to food, and the ability to earn a livelihood), with the urban poor being at risk [50]. Ironically, it's the fundamental duty of the state to observe, respect, protect and fulfil the right to food, and in particular to ensure as a matter of priority that no one goes hungry (Art 21) [25].

The Committee on Socio-economic and Cultural Rights developed the principle of minimum core obligation which requires states to provide basic standards of socio-economic rights (including food) and work upwards towards the full realization of all the rights [51]. The committee, by urging states to put in extra effort in protecting the socio-economic rights of marginalised and vulnerable groups such as those in informal settlements, even in the face of resource scarcity, seemed to have introduced safeguards against state neglect of its minimum core obligation, [52]. Thus in view of the above, countries have an obligation to provide at least a core minimum guarantee of the right to food and work towards realizing this rights to all those who are unable to access food, particularly for vulnerable groups such as those in informal settlements whose livelihoods were disrupted by the pandemic. 
This study provides evidence to plead the governments to respond appropriately and adequately in future emergencies especially with respect to more vulnerable groups. While in agreement with community leaders, the government's COVID19 response measures may have been justifiable with respect to controlling the pandemic hence and thus the public interest in line with the provisions of the Kenyan Constitution [25]. However, such measures need to be necessary, proportionately tailored to their goal, and no more restrictive of fundamental rights than required by the emergency situation in line with the Constitution. Measures against COVID19 should have been implemented in a way that protects, respects and fulfils human rights, and upholds human dignity to the greatest extent possible. It is noteworthy that the government and partners instituted social protection measures to cushion the vulnerable people from the impact of the response measures. However, the implementation of these social protection measures was marred with irregularities that further exacerbated vulnerability to some community members. Further, these social protection measures were notably short-lived as it was anticipated that the COVID19 pandemic would be a temporary problem. This calls for better emergency and disaster preparedness and response measures in the country.

There are a few limitations to this study. First is the use of a convenient sample, selected through purposive sampling technique which may introduce a selection bias. However, researchers included both youth and adults across the two study sites. Secondly, the study was conducted in two of Nairobi's urban informal settlements, therefore, some of the findings may not be generalized to the whole nation because there were variations in the enforcement of the measures in different cities, differences in the environmental setup and household socioeconomic levels. Hence, the perceived effects of the COVID-19 restrictive measures on human right to food may vary from one city to another. However, findings can be generalized to similar vulnerable populations.

\section{Conclusion}

The government of Kenya responded quickly to contain the spread of COVID-19. However, the restrictive measures caused economic disruptions, disrupted sources of the already fragile livelihoods, and increased vulnerability. This exacerbated food insecurity and vulnerability of the urban poor to hunger. Besides, measures by the government and other partners to cushion the most affected people, including cash transfers and food distribution were inadequate, marred by corruption and inequality, unsustainable and only benefited a section of the population. Therefore, in future targeting and recruitment systems should be well coordinated and improved to reach all the needy. Moreover, some of the response measures were implemented in a way that caused violations of the human right to food. Consequently, response measures to pandemics and other misfortunes should be human-centered and executed in ways that guarantee protection of human rights. The pandemic has exposed the fragility of the urban food system. Hence, there is need to strengthen the urban food system to make it more resilient to external shocks.

\section{Declarations}

\section{Ethics approval and consent to participate}

Ethics approval for this study was provided by the African Medical and Research Foundation (AMREF) ethics and scientific review committee. Permission for community entry was sought from the local authorities and community level gatekeepers. The ethical principles guiding research in human subjects in accordance with the Helsinki Declaration, including respect for human autonomy, beneficence, non-maleficence, and justice were 
followed. Participants for both qualitative and participatory methods voluntarily accepted to take part in the study. A written informed consent was sought from the participants before conducting the interviews and a verbal informed consent for phone interviews. Photovoice participants sought permission before taking photos and videos and no faces or identification information of the people, specific premises or structures were taken. Unique identifiers and pseudonyms were used to ensure confidentiality.

\section{Consent for publication}

Not applicable

\section{Availability of data and materials}

The datasets used and/or analysed during the current study are available from the corresponding author on reasonable request.

\section{Competing interests}

The authors declare that they have no competing interests

\section{Funding}

This study was supported by an award from the Arts and Humanities Research Council (AHRC) Global Challenges Research Fund, United Kingdom (AH/V007963/1).

\section{Author contributions}

EWK-M: conceptualized the study, prepared the methodology, acquired funding, investigated the study, performed formal analysis, wrote original draft, reviewed the manuscript and supervised; DO: conceptualized the study, prepared the methodology, monitored data collection/project administration, performed data curation, formal analysis, wrote original draft and reviewed the article; CKN: performed formal analysis, data curation, wrote original draft, reviewed and edited the manuscript; EKI: performed formal analysis, wrote original draft, reviewed, edited the manuscript; DON: participated in writing-reviewing and editing, JH: conceptualized the study, acquired funding, reviewed and edited the manuscript and supervised the study. All authors read and approved the final manuscript.

\section{Acknowledgements}

The authors are grateful to the researchers, policy engagement and communications team at the African Population and Health Research Center (APHRC) who participated in the project including Hilda Owii, Florence Sipalla, Michelle Mbuthia and Faith Kathoka; partners from Katiba Institute including Jill Ghai and Christine Nkonge, Tazama Africa including James Smart and Cardiff University for contribution during the design and implementation of the study. Additionally, the authors are grateful to the respondents who accepted to participate in the study, the data collection and supervision team.

\section{References}


1. Sohrabi C, Alsafi Z, O'Neill N, Khan M, Kerwan A, Al-Jabir A, et al. World Health Organization declares global emergency: A review of the 2019 novel coronavirus (COVID-19). International Journal of Surgery. 2020;76:71-6.

2. Tarrataca L, Dias CM, Haddad DB, De Arruda EF. Flattening the curves: on-off lock-down strategies for COVID-19 with an application to Brazil. Journal of Mathematics in Industry. 2021;11(1):2.

3. Xiao Y, Torok ME. Taking the right measures to control COVID-19. The Lancet Infectious Diseases. 2020;20(5):523-4.

4. Ghosh A, Nundy S, Mallick TK. How India is dealing with COVID-19 pandemic. Sensors International. 2020;1:100021-.

5. Lancet. India under COVID-19 lockdown. Lancet. 2020;395(10233):1315-.

6. Haider N, Osman AY, Gadzekpo A, Akipede GO, Asogun D, Ansumana R, et al. Lockdown measures in response to COVID-19 in nine sub-Saharan African countries. BMJ Global Health. 2020;5(10):e003319.

7. GoK. (Government of Kenya).Kenya Gazette Supplement No. 41. Public Health (COVID-19 Restriction of Movement of Persons and Related Measures) Rules. 6th April 2020 [Accessed January 2021]. Available from: https://ambnairobi.esteri.it/ambasciata_nairobi/resource/doc/2020/04/kenya_gazette__06.04.2020.pdf.

8. Harrington J. Indicators, security and sovereignty during COVID-19 in the Global South. International Journal of Law in Context. 2021;17(2):249-60.

9. Koltai J, Toffolutti V, McKee M, Stuckler D. Prevalence and changes in food-related hardships by socioeconomic and demographic groups during the COVID-19 pandemic in the UK: A longitudinal panel study. The Lancet Regional Health - Europe. 2021;6.

10. Rahman M, Ahmed R, Moitra M, Damschroder L, Brownson R, Chorpita B, et al. Mental Distress and Human Rights Violations During COVID-19: A Rapid Review of the Evidence Informing Rights, Mental Health Needs, and Public Policy Around Vulnerable Populations. Frontiers in Psychiatry. 2021;11(1464).

11. Kansiime MK, Tambo JA, Mugambi I, Bundi M, Kara A, Owuor C. COVID-19 implications on household income and food security in Kenya and Uganda: Findings from a rapid assessment. World development. 2021;137:105199.

12. UN. (United Nations) COVID-19 and Human Rights. We are all in this together 2020 [Accessed June 2021]. Available from:

https://www.un.org/sites/un2.un.org/files/un_policy_brief_on_human_rights_and_covid_23_april_2020.pdf.

13. WHO. (World Health Organization) Addressing Human Rights as Key to the COVID-19 Response 2020 [Accessed June 2021]. Available from: https://www.who.int/publications/i/item/addressing-human-rightsas-key-to-the-covid-19-response.

14. UN. (United Nations General Assembly),Universal Declaration of Human Rights, 10 December 1948 [Accessed May 2021]. Available from: https://www.un.org/en/universal-declaration-human-rights/.

15. OHCHR. International Covenant on Economic, Social and Cultural Rights 1966 [Accessed June 2021]. Available from: https://www.ohchr.org/en/professionalinterest/pages/cescr.aspx.

16. OHCHR. General Comment No 12: The right to adequate food (UN Doc. E/C.12/1999/5 (Twentieth Session). CESCR.Committee on Economic, Social and Cultural Rights of the United Nations 1999 [Accessed May 2021]. Available from: https://www.refworld.org/pdfid/4538838c11.pdf. 
17. Kent G. The Human Right to Food and Dignity. Human Rights. 2010;37(1):2-5.

18. Rosset P. ACHIEVING THE HUMAN RIGHT TO FOOD SECURITY. Race, Poverty \& the Environment. 2000;7(2):21-.

19. Fukuda-Parr SL-R, Terra; and Randolph, Susan. Measuring the Progressive Realization of Human Rights Obligations: An Index of Economic and Social Rights Fulfillment. Economics Working Papers. 200822. 2008 [Accessed August 2021]. Available from: https://opencommons.uconn.edu/econ_wpapers/200822.

20. Chilton M, Rose D. A Rights-Based Approach to Food Insecurity in the United States. American Journal of Public Health. 2009;99(7):1203-11.

21. FAO. The state of food security and nutrition in the world, 2021 [Accessed October 2021]. Available from: https://www.fao.org/publications/sofi/2021/en/.

22. Kimani-Murage EW, Schofield L, Wekesah F, Mohamed S, Mberu B, Ettarh R, et al. Vulnerability to Food Insecurity in Urban Slums: Experiences from Nairobi, Kenya. Journal of Urban Health. 2014;91(6):1098113.

23. Laborde D, Martin W, Swinnen J, Vos R. COVID-19 risks to global food security. Science. 2020;369(6503):500-2.

24. The Lancet Public H. Will the COVID-19 pandemic threaten the SDGs? The Lancet Public Health. 2020;5(9):e460.

25. CoK. (Constitution of Kenya), Kenya Law Organization. Laws of Kenya 2010 [Accessed March 2021]. Available from: http://kenyalaw.org:8181/exist/kenyalex/actview.xql?actid=Const2010.

26. FAO. The right to food within the international framework of human rights and country constitutions 2014 [Accessed July 2021]. Available from: http://www.fao.org/3/i3448e/i3448e.pdf.

27. Neubauer BE, Witkop CT, Varpio L. How phenomenology can help us learn from the experiences of others. Perspectives on Medical Education. 2019;8(2):90-7.

28. Dahlberg K. The essence of essences - the search for meaning structures in phenomenological analysis of lifeworld phenomena. International Journal of Qualitative Studies on Health and Well-being. 2006;1(1):119.

29. Beguy D, Elung'ata P, Mberu B, Oduor C, Wamukoya M, Nganyi B, et al. Health \&amp; Demographic Surveillance System Profile: The Nairobi Urban Health and Demographic Surveillance System (NUHDSS). International Journal of Epidemiology. 2015;44(2):462-71.

30. Wamukoya M, Kadengye DT, Iddi S, Chikozho C. The Nairobi Urban Health and Demographic Surveillance of slum dwellers, 2002-2019: Value, processes, and challenges. Global Epidemiology. 2020;2:100024.

31. Wang C, Burris MA. Photovoice: concept, methodology, and use for participatory needs assessment. Health education \& behavior: the official publication of the Society for Public Health Education. 1997;24(3):36987.

32. Briant KJ, Halter A, Marchello N, Escareño M, Thompson B. The Power of Digital Storytelling as a Culturally Relevant Health Promotion Tool. Health Promot Pract. 2016;17(6):793-801.

33. Braun V, Clarke V. Using thematic analysis in psychology. Qualitative Research in Psychology. 2006;3(2):77-101. 
34. APHRC. Impact of Covid-19 on employment in Nairobi 2021 [Accessed August 2021]. Available from: https://www.youtube.com/watch?v=MEFodgZcVuk.

35. APHRC. Broken homes-families in crisis 2021 [Accessed August 2021]. Available from: https://www.youtube.com/watch?v=a8WY8rloqpl.

36. APHRC. Separated families 2021 [Accessed August 2021]. Available from: https://www.youtube.com/watch?v=htzUNJSoxPU.

37. Robins L CS, van Wensveen M, Alders RG, Bourke RM, Butler J, Cosijn M, Davila F, Lal A, McCarthy JF, McWilliam A, Palo ASM, Thomson N, Warr P \& Webb M COVID-19 and food systems in the Indo-Pacific: An assessment of vulnerabilities, impacts and opportunities for action. ACIAR Technical Report 96,Canberra: 2021: 254 pp.

38. Mboera LEG, Akipede GO, Banerjee A, Cuevas LE, Czypionka T, Khan M, et al. Mitigating lockdown challenges in response to COVID-19 in Sub-Saharan Africa. International Journal of Infectious Diseases. 2020;96:308-10.

39. Sinha D. Hunger and food security in the times of Covid-19 2021 [Accessed June 2021]. Available from: https://doi.org/10.1007/s40847-020-00124-y.

40. Chiwona-Karltun L, Amuakwa-Mensah F, Wamala-Larsson C, Amuakwa-Mensah S, Abu Hatab A, Made N, et al. COVID-19: From health crises to food security anxiety and policy implications. Ambio. 2021;50(4):794811.

41. Bhatt N, Bhatt B, Gurung S, Dahal S, Jaishi AR, Neupane B, et al. Perceptions and experiences of the public regarding the COVID-19 pandemic in Nepal: a qualitative study using phenomenological analysis. BMJ open. 2020;10(12):e043312.

42. Guerra L, Cervato-Mancuso AM, Bezerra ACD. [Food: a disputed human right - a thematic focus for comprehension and action in food and nutritional security]. Ciencia \& saude coletiva. 2019;24(9):3369-94.

43. Saha K, Torous J, Caine ED, De Choudhury M. Psychosocial Effects of the COVID-19 Pandemic: Large-scale Quasi-Experimental Study on Social Media. J Med Internet Res. 2020;22(11):e22600-e.

44. Brodeur A, Gray D, Islam A, Bhuiyan S. A literature review of the economics of COVID-19. Journal of Economic Surveys. 2021;35(4):1007-44.

45. IDRC. Food systems and food security in the time of lockdowns: insights from sub-Saharan Africa 2021 [Accessed August 2021]. Available from: https://www.idrc.ca/en/research-in-action/food-systems-andfood-security-time-lockdowns-insights-sub-saharan-africa.

46. Zhou. J. and C. Delgado. The impact of COVID-19 on critical global food supply chains and food security. 2020 [Accessed June 2021]. Available from: https://www.sipri.org/commentary/topicalbackgrounder/2020/impact-covid-19-critical-global-food-supply-chains-and-food-security.

47. Michael Fakhri. Denisse Córdova Montes, Kadian Crawford,Lucas Dawson,Raul Herrera, Violations of the Human Right to Food During COVID-19 in the United States,United Nations Special Rapporteur on the Right to Food 2019 [Accessed July 2021]. Available from:

https://www.ohchr.org/Documents/Issues/SexualOrientation/IESOGI-COVID-19/academics/MiamiLaw.pdf.

48. Olafsen M, Rukooko AB, Iversen PO, Andreassen BA. Examination of the roles and capacities of duty bearers responsible for protecting the human rights to adequate food, nutritional health and wellbeing in 
Ugandan children's homes. BMC International Health and Human Rights. 2018;18(1):17.

49. FAO. Committee on World Food Security. Impact of COVID-19 on Food Security and Nutrition (FSN). Roma: 2020 [Accessed June 2021]. Available from:

https://www.un.org/sites/un2.un.org/files/sg_policy_brief_on_covid_impact_on_food_security.pdf.

50. HRW. (Human Rights Watch Kenya): Police Brutality During Curfew April 2020 [Accessed November 2021]. Available from: https://www.hrw.org/news/2020/04/22/kenya-police-brutality-during-curfew.

51. Committee on Socio-economic and Cultural Rights, General Comment No 3, 1990 accessed from General comment No. 3: The nature of States parties' obligations (refworld.org). 1990.

52. Young K. Waiting for Rights: Progressive Realization and Lost Time (2019). The Future of Economic and Social Rights,Boston College Law School Legal Studies Research Paper No. 509: Cambridge University Press; 2019 [updated August 2021]. Available from: https://ssrn.com/abstract=3428718.

\section{Tables}


Table 1

General characteristics of the participants

\begin{tabular}{|c|c|c|}
\hline \multirow[t]{2}{*}{ Participants' characteristics } & \multicolumn{2}{|c|}{ Total $n=63$} \\
\hline & $\mathrm{n}$ & $\%$ \\
\hline \multicolumn{3}{|l|}{ Village of residence } \\
\hline Korogocho & 30 & 47.6 \\
\hline Viwandani & 33 & 52.4 \\
\hline \multicolumn{3}{|l|}{ Age group } \\
\hline$<24$ years old & 14 & 22.2 \\
\hline 25-35 years old & 16 & 25.4 \\
\hline $36-55$ years old & 26 & 41.3 \\
\hline 56 years and above & 7 & 11.1 \\
\hline \multicolumn{3}{|l|}{ Gender } \\
\hline Female & 32 & 50.8 \\
\hline Male & 31 & 49.2 \\
\hline \multicolumn{3}{|l|}{ Education level } \\
\hline Elementary school & 29 & 46.0 \\
\hline Secondary school & 27 & 42.9 \\
\hline College/university & 7 & 11.1 \\
\hline \multicolumn{3}{|l|}{ Occupation } \\
\hline Unemployed & 13 & 20.6 \\
\hline Casual labor & 17 & 27.0 \\
\hline Own business & 30 & 47.6 \\
\hline Employed & 3 & 4.8 \\
\hline \multicolumn{3}{|l|}{ Marital status } \\
\hline Married & 32 & 50.8 \\
\hline Single & 24 & 38.1 \\
\hline Divorced/separated & 4 & 6.3 \\
\hline Widowed & 3 & 4.8 \\
\hline \multicolumn{3}{|l|}{ Religion } \\
\hline Christian & 58 & 92.1 \\
\hline
\end{tabular}




\section{Figures}

\begin{tabular}{|lcc|}
\hline Participants' characteristics & \multicolumn{2}{c|}{ Total $\mathbf{n}=63$} \\
\hline Muslim & 5 & 7.9 \\
\hline Ethnicity & & \\
\hline Kikuyu & 20 & 31.7 \\
\hline Luo & 13 & 20.6 \\
\hline Luhya & 12 & 19.0 \\
Kamba & 8 & 12.7 \\
\hline Kisii & 6 & 9.5 \\
\hline Borana & 4 & 6.3 \\
\hline
\end{tabular}

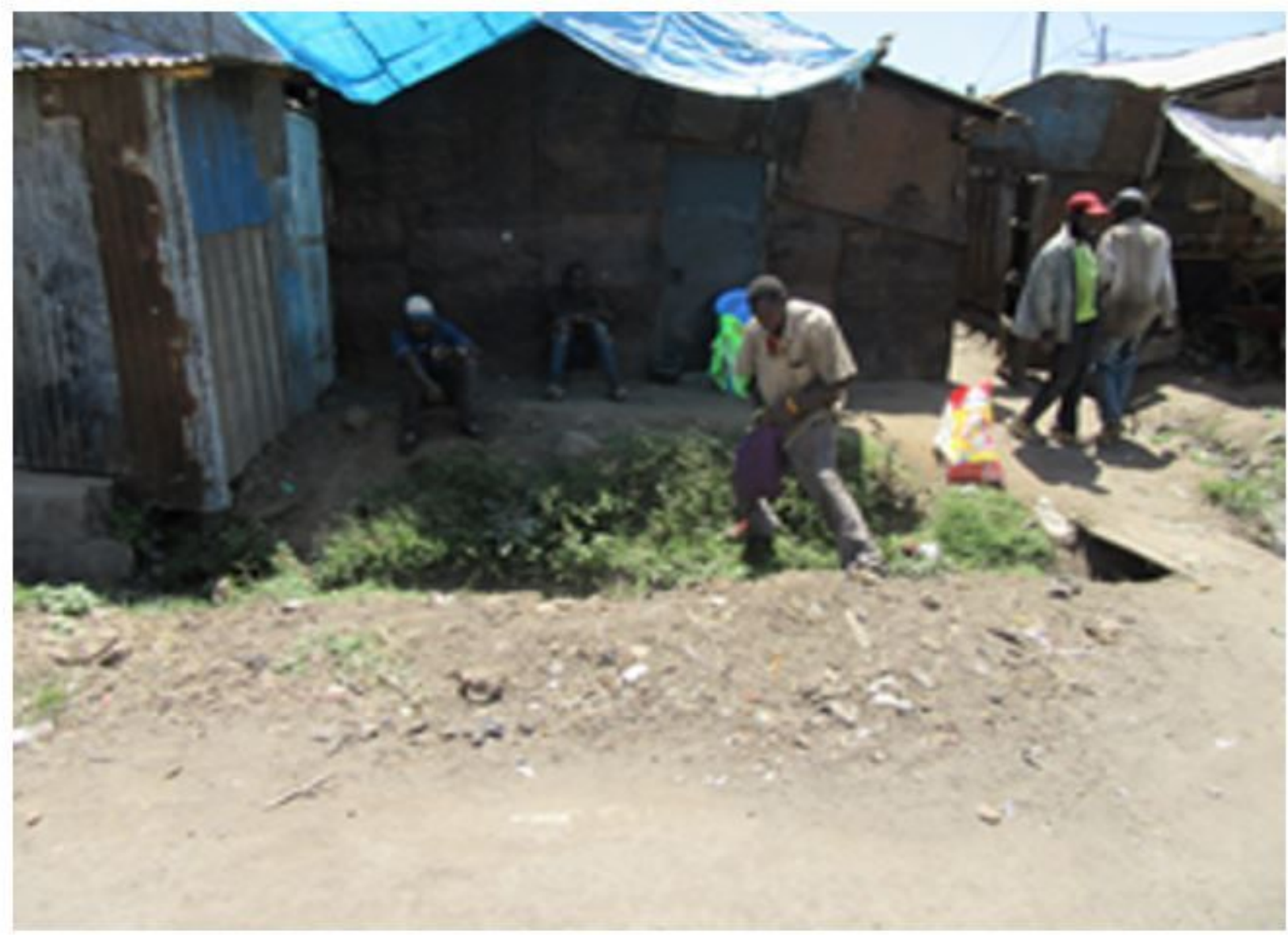

\section{Figure 1}

"... This is the effect of COVID-19 and as you can see in the picture people are idle. So, people have lost their jobs so the picture represents how people are idle in the community." (Photovoice, mixed participants, Korogocho). 


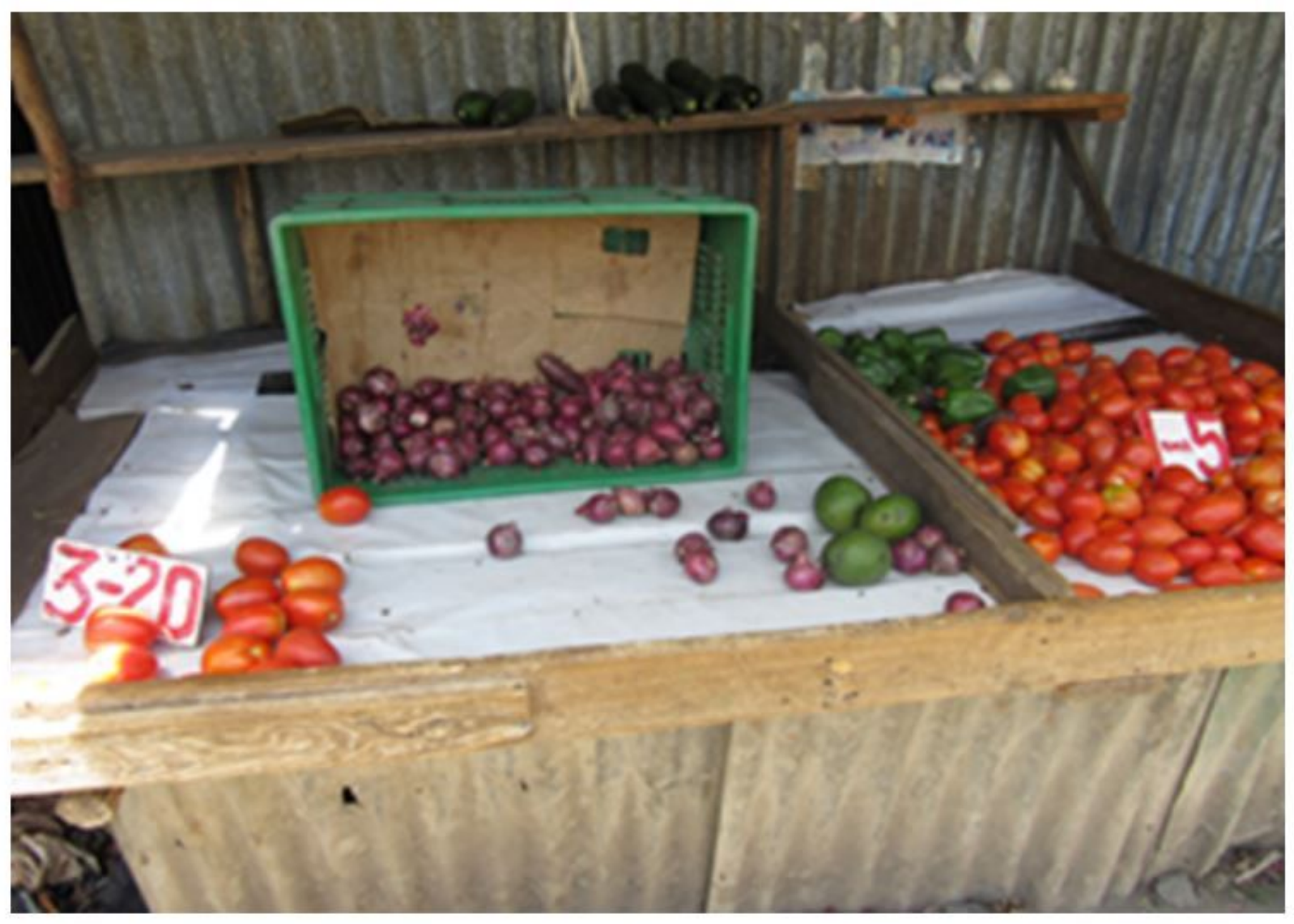

\section{Figure 2}

"...Businesses reduced because people were few in the community and those who were working also reduced so business was really affected. If you look at the photo you will see the market is almost empty. So, businesses went very low..." (Photovoice, mixed group, Viwandani). 


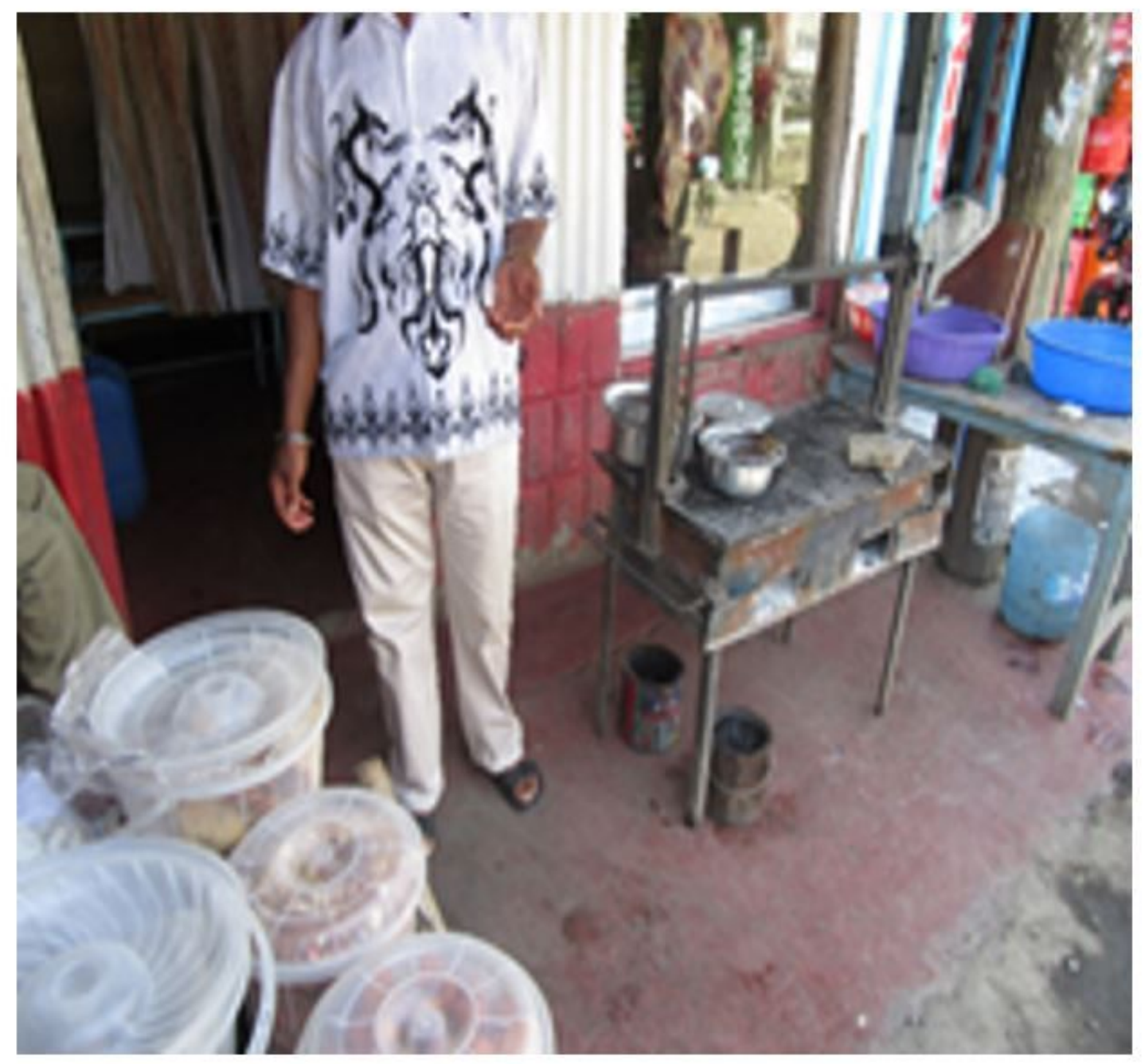

\section{Figure 3}

"...The photo shows a challenge as there is food, but they are not eaten. So, it has affected the community because they don't have money and that's why the businesses people will sell their products for two days or a week and that is costly to them. And it is not even safe as we are supposed to eat fresh foods. But since there is no money people will not buy fresh foods and it's not their liking..." (Photovoice, mixed group, Viwandani). 


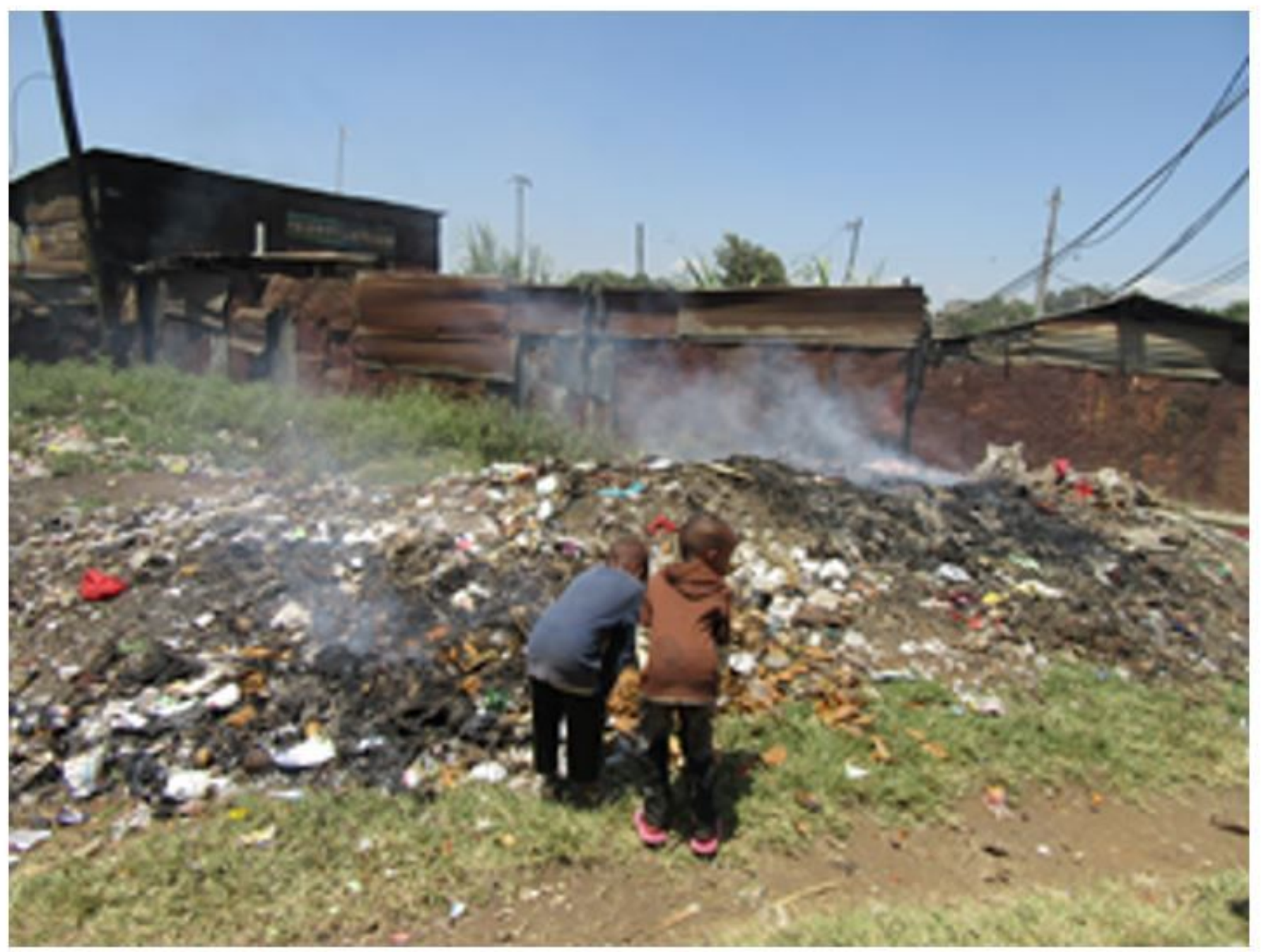

\section{Figure 4}

"...So, the children are at home, and they scavenge the dumpsite for food and if they find something else that they can sell they also go and sell it and get some money to buy something to eat. So all this is the effect of Corona virus which also caused lack of jobs..." (Photovoice, mixed group, Korogocho). 